\title{
Pathologic findings on ruminant enteric clostridial diseases reveal specificities and differences among iota and iota-like toxins
}

\author{
Hallazgos patológicos en las enfermedades entéricas clostridiales en rumiantes \\ revelan especificidades y diferencias entre las toxinas iota y similares
}

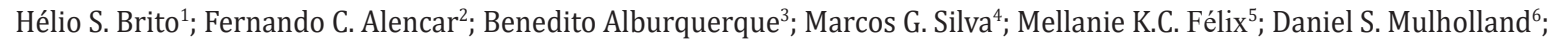
Eugênio E. Oliveira" ; Luis Andre M. Mariúba ${ }^{8}$; Eliane M. S. Santos ${ }^{9}$; Igor V. Brandii ${ }^{10}$; Francisco Carlos F. Lobato ${ }^{11}$; Alex S.R. Cangussu ${ }^{12}$

\begin{abstract}
ARTICLE DATA
1 Pesquisador, M.Sc., Universidade Federal do Tocantins, Gurupi, Tocantins, Brasil, hellyosousa1245@gmail.com; ditoalbuquerque@mail.uft.edu.br

2 Pesquisador, Engenheiro de Bioprocessos e Biotecnologia, Universidade Federal do Tocantins, Gurupi, Tocantins, Brasil, fernandoc.alencar@outlook.com

3 Pesquisador, M.Sc., Universidade Federal do Tocantins, Gurupi, Tocantins, Brasil, hellyosousa1245@gmail.com; ditoalbuquerque@mail.uft.edu.br

4 Professor, Ph.D. Universidade Federal do Tocantins, Gurupi, Tocantins, Brasil, gontijobio@mail.uft.edu.br

5 Pesquisadora, M.Sc., Universidade Federal do Tocantins, Gurupi, Tocantins, Brasil, mellanielorak@hotmail.com

6 Professor, Ph.D. Universidade Federal do Tocantins, Gurupi, Tocantins, Brasil, danielsm@mail.uft.edu.br

${ }^{7}$ Professor, Ph.D. Universidade Federal de Viçosa, Viçosa, MG, Brasil. eugenio@ufv.br

${ }^{8}$ Pesquisador, Ph.D. Instituto Leônidas e Maria Deane, Manaus, Amazonas, Brasil, lamariuba@hotmail.com

9 Professora, Ph.D. Instituto Federal do Norte de Minas Gerais, Araçuaí, MG, Brasil, elianemsobrinho@hotmail.com

10 Professor, Ph.D. Universidade Federal de Minas Gerais, Montes Claros, MG, Brasil, ibrandi@hotmail.com.br

11 Professor, Ph.D. Universidade Federal de Minas Gerais, Belo Horizonte, MG, Brasil, franciscolobato@vetufmg.edu.br

${ }^{12}$ Professor, Ph.D. Universidade Federal do Tocantins, Gurupi, Tocantins, Brasil, alexcangussu@uft.edu.br
\end{abstract}

Cite: Brito, H.S.; Alencar, F.C.; Alburquerque, B.; Silva, M.G; Félix, M.K.C.; Mulholland, D.S; Oliveira, E.E.; Mariúba, L.A.M.; Santos, E.M.S.; Brandi, I.V.; Lobatto, F.C.F.; Cangussu, A.S.R. (2021). Pathologic findings on ruminant enteric clostridial diseases reveal specificities and differences among iot.a and iota-like toxins. Revista de Ciencias Agrícolas. 38(2) 157 - 174.

doi: https://doi.org/10.22267/rcia.213802.154

Recived: Jun 072021

Acepted: August 112021.

\section{ABSTRACT}

The iota toxin (ITX) is a binary enterotoxin produced as a protoxin by Clostridium perfringens (C.perfringens) type E that is activated by proteolytic enzymes in the small intestine of infected animals. By depolymerization of the actin filaments, ITX causes cytoskeleton disorganization of cells promoting the increase of the cell permeability. Here, we conducted this review aiming to advance the understanding of enteric clostridial diseases caused by $C$. perfringens toxins and the specificity of ITX in the intestinal mucosa lesions. ITX consists of an enzymatic component (Ia) and a binding component $(I b)$. We screened the recently published histological findings of the ITX effects and its relationship with intestinal enteric diseases. Histologically, hemorrhagic necrosis and multifocal hemorrhage have been observed in the jejunum-ileum mucosa, the small intestine, and the abomasum. Although the diagnosis is still based on the presence of toxins in the intestinal contents and the clinical and/or histological history, it is important to develop novel enterotoxemic indicators capable of establishing precise methods for differentiate the actions of ITX and other toxins involved in the infectious process of $C$. perfringens type $\mathrm{E}$.

Keywords: iota toxin; iota like toxin; binary toxins; C. perfringens type E; enterotoxemia.

\section{RESUMEN}

La toxina iota (ITX) es una enterotoxina binaria producida como protoxina por Clostridium perfringens (C. perfringens) tipo E que es activada por enzimas proteolíticas en el intestino delgado de los animales infectados. Mediante la despolimerización de los filamentos de actina, la ITX provoca la desorganización del citoesqueleto de las células promoviendo el aumento de la permeabilidad celular. 
Aquí, realizamos esta revisión con el objetivo de avanzar en la comprensión de las enfermedades entéricas clostridiales causadas por las toxinas de $C$. perfringens y la especificidad de ITX en las lesiones de la mucosa intestinal. La ITX consta de un componente enzimático ( $I a$ ) y un componente de unión (Ib). Examinamos los hallazgos histológicos recientemente publicados sobre los efectos de la ITX y su relación con las enfermedades entéricas intestinales. Histológicamente, se ha observado necrosis hemorrágica y hemorragia multifocal en la mucosa del yeyuno-ileo, el intestino delgado y el abomaso. Aunque el diagnóstico sigue basándose en la presencia de toxinas en el contenido intestinal y en la historia clínica y/o histológica, es importante desarrollar nuevos indicadores enterotóxicos capaces de establecer métodos precisos para diferenciar las acciones de la ITX y de otras toxinas implicadas en el proceso infeccioso de C. perfringens tipo E.

Palabras clave: toxina iota; toxina similar a la iota; toxinas binarias; C. perfringens tipo E; enterotoxemia.

\section{INTRODUCTION}

Clostridium is a genus of bacteria characterized by being mobile anaerobic rods capable of forming spores. It thrives in poorly drained pastures and alkaline soils (Li et al., 2013; Sari et al.,2016). Their strains cause the disease by the production of toxins or by tissue invasion, which may differ according to the synthesis of the genes (Li et al., 2013; Fuentes et al., 2016; Felix et al., 2019). For instance, enteritis and enterotoxemia are diseases caused by toxins produced by strains of $C$. perfringens in the intestine and their distribution to organs of infected animals. These toxins cause skin diseases, damage to subcutaneous and muscular tissue, gas gangrene or malignant edema, mostly mediated by one or more toxins produced by C. perfringens (Manteca et al., 2002; Waters et al., 2005; Uzal et al., 2010; Brandi et al., 2014; Freedman et al., 2015).

The iota toxin (ITX) is a binary enterotoxin produced as a protoxin by C. perfringens type $E$, which can be activated in the presence of proteolytic enzymes. Its mechanism of action involves the disorganization of cell cytoskeleton through the depolymerization of actin filaments and the inhibition of cell functions that are dependent on the cytoskeleton, resulting in cell death (Prescott et al., 2016; Navarro et al., 2018). ITX consists of an enzymatic ( $I a$ ) and a binding (Ib) component (Sakurai et al., 2009). Alone each component is not toxic, but combined, Ia and $I b$ are cytotoxic to multiple cells (Sakurai et al., 2009; Uzal et al., 2018; MehdizadehGohari et al., 2021). The specificity and participation of ITX in enteric diseases and its effects in the intestine are still not completely elucidated (Navarro et al., 2019). However, recent histological and immunohistochemical results obtained from sections of the jejunum and ileum have contributed to a better understanding of the mechanism of action of ITX and other toxins. Such findings have also contributed to advancing methods to differentiate cause and effect in the structure of the intestinal mucosa of infected animals.

By reviewing the recent histological findings, the present review aims to advance the state of the art of iota toxin and thus the understanding of enteric diseases caused by $C$. perfringens. It also aims to indicate the mechanism of action of ITX on the intestinal mucosa of infected animals, which can improve the differential diagnosis of enteric diseases.

Perfringens, toxins, and intestinal diseases. $C$. perfringens has already been 
classified into five types major (A, B, C, D, and E) based on its ability to encode four typing toxins, i.e., alpha (CPA), beta (CPB), epsilon (ETX), iota (ITX) (Uzal, 2004). However, the $\mathrm{F}$ and $\mathrm{G}$ types with their respective $\mathrm{CPE}$ and NetB toxins have been proposed by Rood et al. (2018) (Table 1). CPA contains two domains, an $\mathrm{N}$-terminal alpha-helical domain that contains the active phospholipase $\mathrm{C}$ site, and a C-terminal alpha-sandwich domain that is involved in membrane binding (Uzal et al., 2010). The gene that encodes CPA is located in a stable region within the bacterial chromosome and is present in all C. perfringens isolates (Jewell et al., 2015). In addition, individual strains of each toxin type can also produce one or more variety of so-called non-typifying toxins, such as perfringolysin $\mathrm{O}$ (PFO). PFO is a cholesteroldependent cytolysin capable to form pores in the plasma membrane acting synergistically to CPA (Awad et al., 1995). This synergetic interaction is due to the action of CPA that facilitates the interaction of PFO with the cholesterol present in the lipid bilayer (Uzal et al., 2016). CPA and PFO induce vascular occlusion, which blocks blood flow and leads to the formation of an ischemic zone, causing a leukostasis condition, in which leukocytes are unable to move freely (Chakravorty et al., 2014).

C. perfringens toxin types cause several different enteric diseases in humans and animals. These diseases are mediated by one or more toxins from C. perfringens (Uzal et al., 2016). Among the enteric infections associated with $C$. perfringens, the type $\mathrm{C}$ strains have been confirmed to affect humans and animals (Uzal et al., 2016), whereas other toxin types were described to cause disease in humans or animals individually (Navarro et al., 2019). The virulence of $C$. perfringens is largely attributed to its ability to produce a variety of different extracellular enzymes and toxins (Table 1). C. perfringens type $\mathrm{C}$ produce CPA, CPB, and PFO toxins (Vidal et al., 2009).

CPB is encoded as a prototoxin and is characterized by being extremely sensitive to trypsin and other proteases (Miclard et al., 2009a). The pathology of spontaneous disease associated with CPB is characterized by hemorrhage and necrosis of the epithelium of the small intestine and sometimes in the large intestine (Miclard et al., 2009b).

Table 1. Toxins produced by C. perfringens and correlated genes.

\begin{tabular}{ccccccc}
\hline Type & $\begin{array}{c}\text { CPE } \\
\text { (plc ou cpa) }^{*}\end{array}$ & $\begin{array}{c}\text { CPB } \\
\text { (cpb) }\end{array}$ & $\begin{array}{c}\text { CPX } \\
(\text { etx) }\end{array}$ & $\begin{array}{c}\text { ITX } \\
\text { (iap e ibp) }^{*}\end{array}$ & $\begin{array}{c}\text { CPE } \\
\text { (cpe) }\end{array}$ & $\begin{array}{c}\text { NetB } \\
\text { (netb) }\end{array}$ \\
\hline A & + & - & - & - & - & - \\
$\mathrm{B}$ & + & + & + & - & - & - \\
$\mathrm{C}$ & + & + & - & - & $+/-$ & - \\
$\mathrm{D}$ & + & - & + & - & $+/-$ & - \\
$\mathrm{E}$ & + & - & - & + & $+/-$ & - \\
$\mathrm{F}$ & + & - & - & - & + & - \\
$\mathrm{G}$ & + & - & - & - & - & + \\
\hline
\end{tabular}

* structural genes from C. perfringens toxins are represented in parentheses. (+) present; $(-)$ absent 
The damage associated with CPB starts in the intestinal mucosa but can progress to all layers of the intestine. Fibrin thrombi that occlude the superficial microvasculature present in the lamina propria are characteristic of intestinal disease associated with CPB (Schumacher et al., 2013). ETX is produced by $C$. perfringens type $\mathrm{D}$, which has an action on the endothelium of vessels increasing vascular permeability.

These strains are the most common cause of enterotoxemia in sheep and goats. The histological changes observed in enterotoxemia caused by $C$. perfringens type D have been evidenced by intravenous inoculation experiments with ETX in sheep and goats (Uzal and Kelly, 1997). Postmortem findings of cattle brain revealed proteinaceous perivascular edema that affected both small to medium size arteries and veins, with the perivascular spaces of several blood vessels being distended by eosinophilic and homogeneous fluid (Filho et al., 2009).

The lesions most commonly observed in the corpus striatum, mesencephalon, cerebellar white matter, and cerebellar peduncles are multifocal, acute, mild hemorrhage of the lamina in the jejunum (Filho et al., 2009). ETX is also secreted as a low activity prototoxin. In the intestine, ETX is activated by proteases, such as trypsin, $\alpha$-chymotrypsin, carboxypeptidases and / or sometimes by $\lambda$-protease (Minami et al., 1997; Harkness et al., 2012).

CPE is a protein made up of a $\mathrm{N}$-terminal domain (important for the formation of pores and cytotoxicity) and a C-terminal domain that mediates binding to the receptor, being secreted mainly by the $C$. perfringens enterotoxin strain (Van Itallie et al., 2008; Rood et al., 2018). The C-terminal region of the toxin is related to cytotoxic activity, but it also mediates the binding to the receptor, which involves the presence of several tyrosine residues located in the last 30 amino acids of CPE (Harada et al., 2007; Takahashi et al., 2008). On the other hand, the N-terminal is particularly important for cytotoxicity, given its fundamental role in the oligomerization and formation of EPC pores (Smedley and McClane, 2004).

NetB is produced by strains of $C$. perfringens type G (Rood et al., 2018). This strain is among the most common and important pathogens in humans and animals (Uzal et al., 2018). C. perfringens type G causes histotoxic infections, including gas gangrene (myonecrosis), anaerobic cellulitis, and simple wound infections (Songer, 1996). It is also responsible for several human and animal diseases originated in the intestine. These diseases are often manifested as enteritis or enterotoxemia, a condition in which toxins produced in the intestines are absorbed into the circulation and then damage other internal organs such as the brain, lungs, or kidneys (Shrestha et al., 2019). Studies have confirmed that NetB is the main virulence factor involved in the development of avian necrotic enteritis, evidenced by epidemiological damage (Keyburn et al., 2010; Prescott et al., 2016; Rood et al., 2016). Table 2 shows the main properties of the mentioned toxins.

Perfringens ITX. ITX is a member of the binary toxin family that consists of separate Ia and Ib proteins produced as pro-proteins and enzymatically activated by removal of their N-terminal sequences by the host proteases (Sakurai et al., 2009) (Figure 1). 
Table 2. Toxin data from C. perfringens

(Adapted from Uzal et al., 2010; Li et al., 2013; Navarro et al., 2018).

\begin{tabular}{ccll}
\hline Gene & \multicolumn{1}{c}{ Size } & \multicolumn{1}{c}{ Biological Activity } & Molecular weight \\
\hline cpa & $370 \mathrm{pb}$ & $\begin{array}{l}\text { Necrotizing Hemolytic Contraction } \\
\text { of smooth muscle }\end{array}$ & $42,5 \mathrm{KDa}$ \\
$\mathrm{cpb}$ & $336 \mathrm{pb}$ & $\begin{array}{l}\text { Dermonecrotic edema, enterotoxic, cytotoxic } \\
\text { Lethal dermonecrotic edema }\end{array}$ & $35 \mathrm{KDa}$ \\
etx & $656 \mathrm{pb}$ & $\begin{array}{l}\text { Smooth muscle contraction } \\
\text { Sma }\end{array}$ & $\begin{array}{l}\text { Ia: } 47,5 \mathrm{KDa} \\
\text { Ib: 71,5 KDa }\end{array}$ \\
iap & $135 \mathrm{~kb}$ & Lethal necrosant & $35 \mathrm{KDa}$ \\
cep & $319 \mathrm{pb}$ & Lethal enterotoxic erythema & $33 \mathrm{KDa}$ \\
\hline
\end{tabular}

A

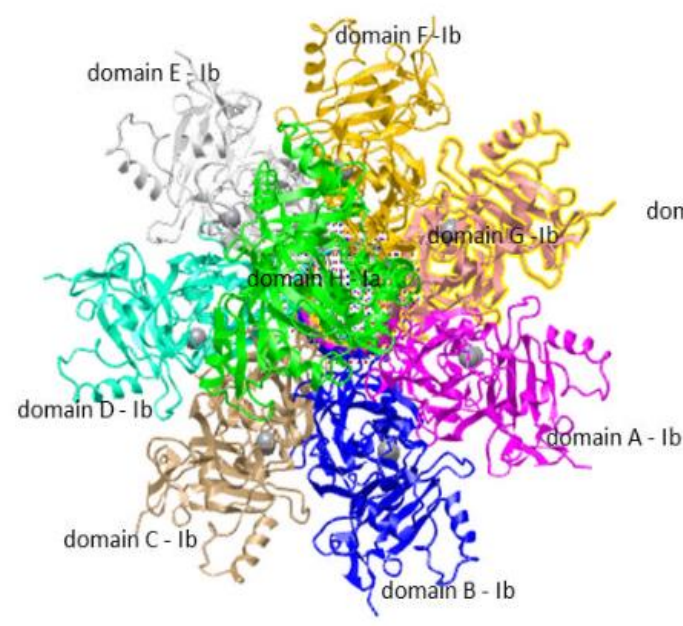

B

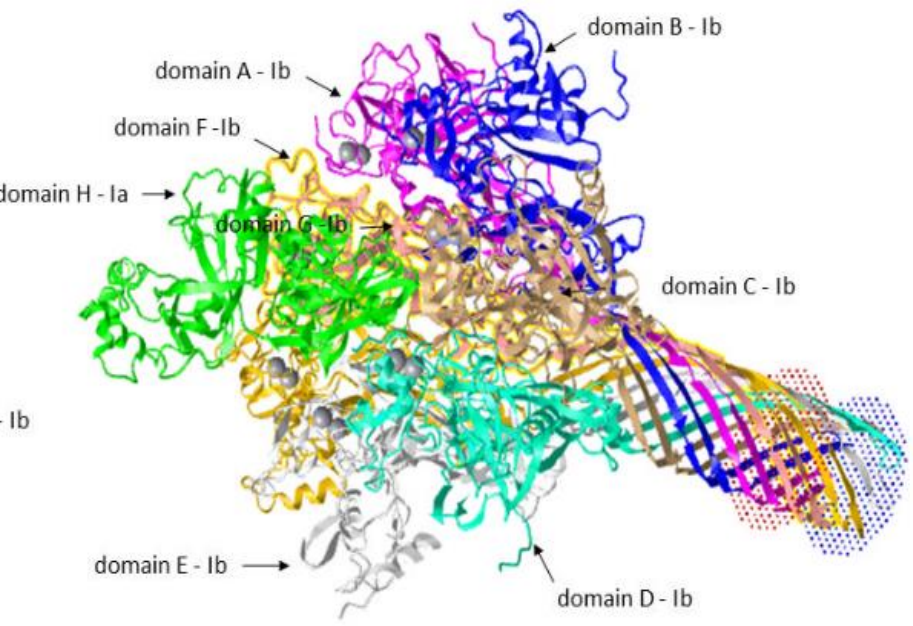

Figure 1. ITX structure of $C$. perfringens type E. (A) and (B) showing the position of Ia and Ib domains and components responsible for the interaction and depolarization of host cells (adapted from Yamada et al., (2020)).

The component Ia consists of a N-terminal domain that interacts with $\mathrm{Ib}$ and a C-terminal domain with ADP-ribosyltransferase activity. The N-terminal end contains the Ib binding site, and the C-terminal end contains the active ADP-ribosylation site (Li et al., 2013; Simpson et al., 2018). The component Ib has four domains that allow the interactions of Ia and the internalization along with host cell ligands. The I domain of Ib is responsible for proteolytic activation; the II domain is responsible for binding to the cell plasma membrane and pore formation; the III domain is responsible for polymerization; and the IV 
domain is responsible for receptor binding. The latter is similar among all toxins in this group (Li et al., 2013; Schmidt et al., 2015).

The action of ITX starts with the Ib binding to the specific LSR receptor (a lipoprotein receptor that is stimulated by lipolysis present in the cell membrane). This interaction leads to the formation of lipid structures in the form of metamers (Figure 1) (Schmidt et al., 2015). The formed complex interacts with eukaryotic cells and serves as a binding site for Ia (Knapp et al., 2009), and part of Ib is recycled back to the plasma membrane with Ia absorption increase. The complex of Ia and Ib are transported to the initial endosomes, where acidification promotes the cytosolic entry of Ia. The $\mathrm{C}$ domain and part of the $\mathrm{N}$ domain of Ia bind to G-actin in the cytosol and causes ADP ribosylation, blocking the polymerization of actin, and finally, intoxicating the cells (Tsuge et al., 2003) (Figure 1).

The action mechanism of $C$. perfringens ITX. The lipolysis-stimulated lipoprotein receptor (LSR) has been reported as a cellular receptor for Ib, which mediates toxin entry into host cells (Schmidt et al., 2015). The ITX entry into host cells may involve associated endocytosis to the CD44 cell surface antigen (Wigelsworth et al., 2012). Once bound to its receptor, Ib assembles into heptamers that are inserted into the host's plasma membrane, forming functional channels and allowing the movement of ions and Ia translocation and endocytosis (Nagahama et al., 2002; Nagahama, 2012). The Ia enzymatic component is also secreted as an inactive form that needs the proteolytic removal of 9 to 11 $\mathrm{N}$-terminal residues (Gibert et al., 2000). The $\mathrm{C}$-domain of Ia is responsible for the toxin's ADP ribosylation activity, which involves the covalent attachment of ADP-ribose to an
Arginine at the actin residue 177 (Tsuge et al., 2003). This leads to the depolymerization of actin filaments and increase in G-actin monomers (Tsuge et al., 2008).

The depolymerization of the actin cytoskeleton results in changes in cell morphology and disorganization of the intercellular and basolateral junctions, leading to an increase in the permeability of cultured monolayers of intestinal cells (Nagahama et al., 2012).

Both ITX components internalize into target cells through a Rho-dependent pathway (independent of clathrin) and reach endocytic vesicles (Gibert et al., 2011), with the return of part of $\mathrm{Ib}$ that is recycled to the plasma membrane (Takehara et al., 2017). At the end of endocytosis, Ia translocates from the late endosomes to the cytoplasm, where it exerts its ADP-ribosylating activity. This translocation requires an acidic environment present in the late endosomes (Gibert et al., 2007), with a change in morphology (rounding), the inhibition of leukocyte migration and activation, the inhibition of smooth muscle contraction, and the impairment of endocytosis, exocytosis, and cytokinesis (Richard et al., 2002).

Network of interactions of $C$. perfringens and ITX toxins. The protein interaction network that involves ITX is not fully known. Therefore, a detailed investigation of how this toxin interacts with other proteins in the network is necessary. Bioinformatics analysis makes possible to carry out a quick analysis of data (Alves et al., 2014). Thus, through these analyses, it is possible to reveal molecules and mechanisms important in the pathogenesis of human and animal diseases never addressed in the literature, clarifying the ways in which different molecules act. As a way of raising 
hypotheses for the performance of ITX in enteric diseases caused by $C$. perfringens, maps of protein interactions were built using the STRING software (Szklarczyk et al., 2021), obtaining the networks represented in Figure 2.

The inputs used in the creation of the networks were "Clostridium perfringens" and "Toxin". In each elaborated network, the leader gene was selected. The selected gene was the one that presented the highest number of interactions within each network:
PFO - Perfringolysin O, CPF_0291, CPF_1586, CPF_0971.

PFO is expressed in almost all identified strains of $C$. perfringens and has interesting characteristics that suggest an undefined potential role for PFO in the development of clostridial diseases. A role for PFO in the progression of gas gangrene and bovine necrohemorrhagic enteritis has been demonstrated, but limited data are available to determine whether PFO also works in presentations of additional diseases caused by C. perfringens (PMID: 26008232).
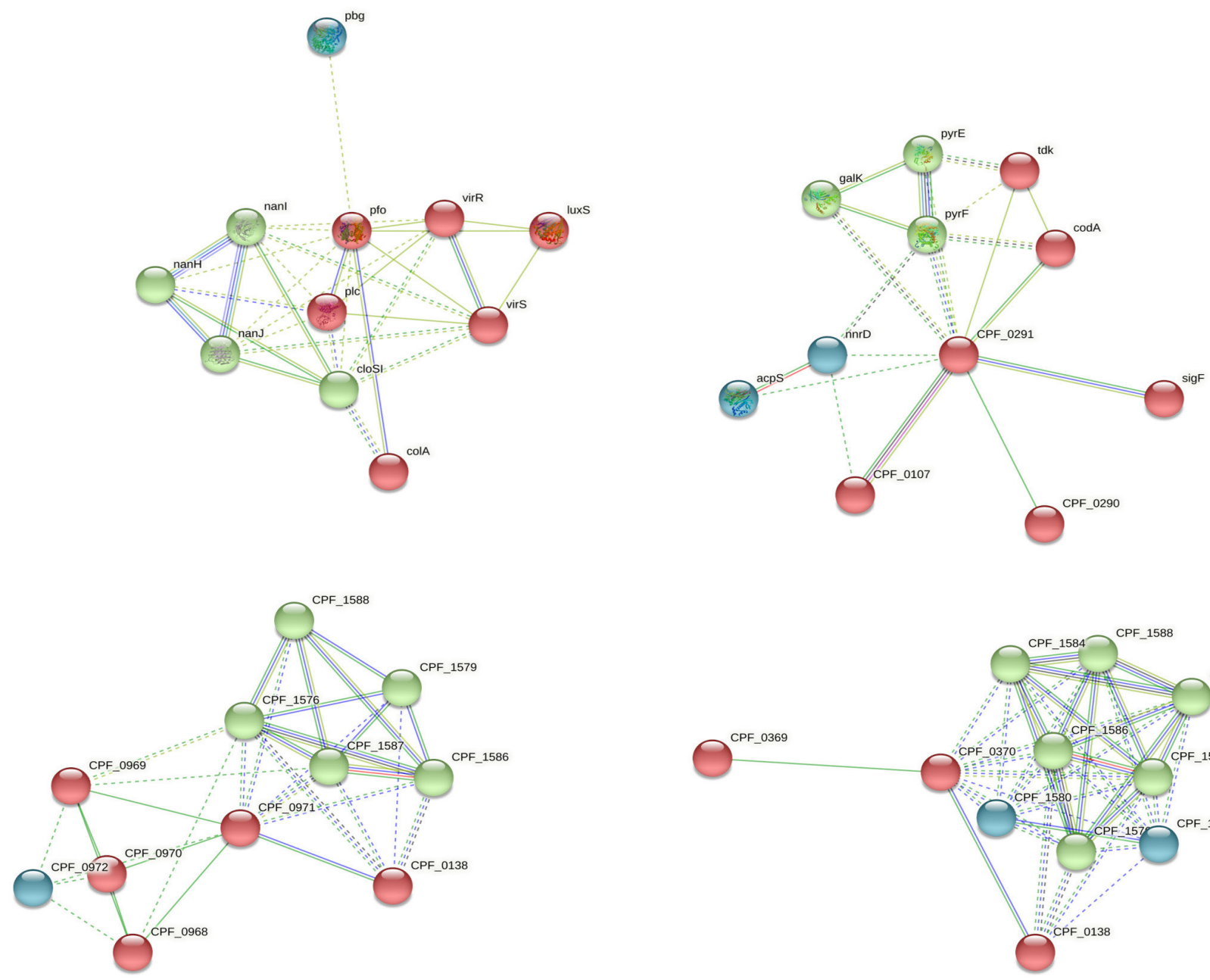

Figure 2. Interaction network from C. perfringens toxins using Perfringolysin $O$ by software STRING. 
Therefore, it is interesting to investigate the type of interaction of ITX with PFO to unravel an ITX acting possibility through the oligomeric pore complex. Studies have reported that binary clostridial toxins induce disruption of the actin cytoskeleton through the mono-ADP-ribosylation of globular actin and are responsible for enteric diseases. These toxins share structurally and functionally related binding components that recognize specific cell receptors, oligomerize, form pores in the membrane of the endocytic vesicle, and mediate the transport of the enzyme component to the cytosol. The binding components retain the overall structure of toxins such as PFO. However, its pore-forming activity (namely clostridial binding components) is more related to the aerolysin and epsilon toxin of C. perfringens (Knapp et al., 2016). As a result, it is important to focus on the ITX pore-forming activity.

The interaction possibilities between ITX and the other leading genes identified in bioinformatics analysis also needs further investigation. CPF_0291 is an mRNA interferase, toxic component of a toxinantitoxin (TA) module. CPF_1586 is a phage portal protein, family HK97, identified by correspondence with the family of proteins HMM PF04860; it corresponds to the HMM family of proteins TIGR01537. CPF_0971 is characterized by the secretion of toxins / phage lysis holin; identified by correspondence with the HMM family of proteins PF05105; it corresponds to the HMM family of proteins TIGR01593.

Studies of molecular interactions of ITX of $C$. perfringens type E. The ITX of $C$. perfringens type $\mathrm{E}$ belongs to the family of binary toxins, in which the translocation and enzyme domains are in two individual unbound proteins (Stiles and Wilkins, 1986). Pore Ib comprises four domains: 1 (domain 1 without the propeptide), 2, 3 and 4, as with protective antigen (PA). The main pore comprises domain 2, which consists of two parts designated as 2c (296-311 aa and 381-512 aa) and 2s (312-380 aa). Domain $2 s$ is an extended $\beta$ clamp, seven copies of which come together to form a 14-filament $\beta$ barrel spanning the membrane. Domain 3 located in an intermediate position between domains $1^{\prime}$ and 2c. Domain 4 is the receptorbinding domain consisting of 260 amino acid residues (616-875 aa) and is located in the outermost region of the pore (Yamada et al., 2020). Tsuge et al. (2008) determined the recognition structure of Ia to actin, where Ia recognizes the actin by five loops around NAD: loop I (Tyr-60-Tyr-62 in the N domain), loop II (the loop of the site active connecting $\alpha 7$ and $\alpha 8$ propellers), loop III (the loop between $\beta 9$ and $\alpha 10$ ), loop IV (the PN loop located at 10 residues after the serine-threonine-serine (STS) motif that stabilizes the NAD connection), and loop $\mathrm{V}$ (the ADP-ribosylation turn-turn - ARTT loop that contains Motif EXE). The EXE motif includes two key glutamate residues, and it is present in the catalytic center. Actin is recognized by loops III, IV and V through not only the ionic interaction, but also through the van der Waals interaction, based on the complementary form.

Although the Ia enzymatic component (ADPribosyltransferase) changes from the cis side to the trans side, the Ib pore has a clamp and four constriction sites that are classified based on the change in their diameter. The first constriction site is composed of dicalcium binding sites unique by $\mathrm{N}$-terminals designated as the Ca edge with an inner diameter of $45 \AA$. The second constriction site consists of NSQ loops (490-492 aa) with an 
internal diameter of $23 \AA$. . Ca-edges and NSQ loops function as the most important region for the binding of Ia. The third constriction site is composed of TEG loops (497-499) with an internal diameter of $22 \AA$. The narrowest clamp is formed by seven $\mathrm{F} 454 \mathrm{~s}$ of protomers with an internal diameter of $6 \AA$, called clamp $\phi$ in PA. The fourth site of constriction is composed of His 313 located in the vestibule of the stem. Therefore, the inner pore surface is divided into layers I, II, III, IV and V from cis- to trans-based on the four constriction sites and a clamp (Yamada et al., 2020).

The polar side chains of EXE extend towards the catalytic cavity and are the common sequence involved in the formation of the $\mathrm{NAD}+$ crack and an aromatic residue- $\mathrm{R} / \mathrm{H}$, located in the cavity where it binds to NAD+. Glu-378 and -380 in Ia are included in the EXE sequence and is essential for enzymatic activity. Arg-295 is present in the aromatic residue$\mathrm{R} / \mathrm{H}$ sequence (Domenighini and Rappuoli, 1996). The substitution of Arg-295 for alanine in Ia causes complete loss of NADase, ARTase, lethal and cytotoxic activities (Nagahama et al., 2000). The replacement of Arg-295 by a basic amino acid, such as histidine or lysine, also generates a drastic reduction in the activities of NADase and ARTase, showing that Arg-295 cannot be replaced by other basic residues. The side chain of Arg-295 is essential for the NADase and ARTase activities of Ia. Arg-295 plays an essential role in binding Ia to NAD+ (Perelle et al., 1996).

The substitution of Glu-378 in the EXE sequence for alanine in Ia results in the complete loss of NADase and ARTase activities (Nagahama et al., 2000). However, the replacement of Glu-378 with aspartic acid causes a low effect on the NADase activity, but a drastic reduction in the ARTase activity.
These results indicate that Glu-378 plays an important role in ARTase activity but not in NADase activity. Therefore, it is likely that the side chain carboxyl group at the amino acid at position 378 is not required for NADase activity, but it is essential for ARTase activity (Perelle et al., 1996). Alterations in the peptide sequence of the EXE motif of Ia may represent a way to advance the specificity and pathogenicity of ITX as well as to be explored in the development of methods that differentiate the lesions caused by ITX and iota like toxins.

\section{Diagnostic methods for enteric diseases.} In South American and European countries, diagnoses of enteric diseases are performed by analyzing clinical signs, characterization of macroscopic and microscopic lesions, detection of the $C$. perfringens toxins type present in the intestinal contents of infected animals by ELISA and PCR, isolation of the etiological agent in bacteriological cultures, demonstration of toxins in clinical samples and in supernatant fluid from pure cultures, or by Seroneutralization of the intestinal filtrate combined with specific antitoxins (Sobrinho et al., 2010; Sobrinho et al., 2014; Silva et al., 2015; Santana et al., 2018; Ghoneim and Hamza, 2017). PCR is a basic molecular technique that can be employed to detect $C$. perfringens strains by in vitro Multiplex PCR tests, in which the corresponding toxin genes are detected. This allows the typification of the causative agent of the lesion (Redondo et al., 2013; Lobato et al., 2013; Park et al., 2016). The dermonecrotic effect can be performed in guinea pigs, using standard antitoxins (anti-CPA, anti-CPB, anti-EPX and anti-ITXı) applied for the typification of $C$. perfringens type E (Fleming et al., 1985; Brandi et al., 2016; Ghoneim and Hamza, 2017; Santana et al., 2018). 
Enterotoxemia caused by the action of ITX presents similarities between intestinal lesions and lesions caused by toxins from other strains of $C$. perfringens, which makes it difficult to apply the protocol used for enterotoxemia caused by C. perfringens type D. In addition, there are cross-reactions between ITX and iota-like toxins that make it difficult to determine the specificity of ITX in lesions (Uzal, 2004; Navarro et al., 2019). The infection caused by the epsilon toxin of C. perfringens type D, which usually affects animals between three days and six months of age, must be made at the beginning of the infection process (Lobato et al., 2000). Infected animals may have more fluid and dark feces, difficulty walking, lateral decubitus, and death with autopsies revealing changes in the small intestine with petechiae, edema, and dark yellow intestinal contents (Lobato et al., 2000). Data on the infection history, pathological, microbiological and seroneutralization findings in mice allow the conclusive diagnosis of enterotoxemia caused by C. perfringens type D (Lobato et al., 2000; Moreira et al., 2016).

In Brazil, the diagnosis of enteric diseases is mostly clinical and empirical. The diagnosis confirmation is done by detecting the toxin type found in the intestinal contents of infected animals and using the serumneutralization technique. However, there is a need for improvement and implementation of laboratory infrastructure and the development of new, safe and validated in vitro methodologies that will replace in vivo techniques (Miyashiro et al., 2009).

Pathological findings on enteric diseases and infections by ITX. C. perfringens strains can cause intestinal infections, including enteritis and enterotoxemia due to the action of toxins in the intestine of infected animals and/or other organs (Sayeed et al., 2008). Toxin action has resulted in skin, subcutaneous and muscle tissue diseases, gas gangrene or malignant edema, most of which are mediated by one or more toxins produced by C. perfringens (Uzal et al., 2010; Freedman et al., 2015; Brandi et al., 2016). Reports from Diab et al. (2012) confirmed cases of enterotoxemia caused by $C$. perfringens toxin type $\mathrm{C}$ in foals and horses, with segmental multifocal hemorrhage and thickening of the intestinal wall of the colon and cecum. Animals presented variable amounts of hemorrhagic fluid in the intestinal contents, characterized by necrotic enteritis and a high concentration of gram-positive rods present in the mucosa. Clinical analysis, macroscopic and histological lesions, and detection by serum neutralization confirmed the presence of beta toxin in the intestinal contents. The characteristics and clinical signs described for infections caused by C. perfringens type $\mathrm{C}$ and $C$. spiroforme are similar to those caused by ITX of $C$. perfringens type E (Songer, 1996; Songer and Miskimmins, 2004; Navarro et. al., 2019). Infections caused by $C$. spiroforme toxins are clinically characterized by diarrhea and hemorrhagic lesions, characteristic of the cecal serosa and mucosa, and eventually, the distal ileum and proximal colon with the presence of aqueous mucoid content (Borriello and Carman, 1983; Carman and Borriello, 1984).

In South American countries, C. perfringens type $\mathrm{E}$ has been isolated in a relatively high proportion, with a prevalence of iota toxin in almost $30 \%$ of samples from healthy and diarrheal calves (Miyashiro et al., 2009) and $9 \%$ of calves samples with sudden death (Ferrarezi et al., 2008). The enterotoxemia caused by ITX in calves and lambs has 
been reported since 1963 in Great Britain. However, postmortem findings have always been referred to as hemorrhagic necrotic enteritis in calves, in which ITX was detected in the intestinal fluids of sheep and cattle (Redondo et al., 2015). ITX can also cause enterotoxemia in lambs, calves, and rabbits. However, these reports are described with lower prevalence (Filho et al., 2009; Kim et al., 2013; Redondo et al., 2015). Little is known about the pathogenesis of $C$. perfringens type $\mathrm{E}$ infections, however, it is assumed that, according to the standard established for isolates that produce other types of toxins, ITX plays an important role, requiring a more accurate and direct diagnosis and a better comprehension of its specificity in intestinal lesions.

To establish advances in the diagnosis and specificity of $C$. perfringens type $\mathrm{E}$ iota toxin in intestinal lesions, it is necessary to evaluate, through retrospective studies, postmortem clinical data from infected animals. Postmortem data of infections have already revealed the presence of multifocal mucosal hemorrhage in the abomasum and small intestine and hemorrhagic necrosis of the superficial mucosa in the jejunumileum. Hemorrhagic necrosis has been the main intestinal lesion caused by iota toxin of $C$. perfringens type E (Filho et al., 2009; Redondo et al., 2015). Mild autolytic change in segments of the jejunum, ileum, and colon, with some necrotic areas of the ileum and with signs of lymphadenitis, has also been described (Redondo et al. 2013). Stretch marks caused by inflammation were seen on the mucosal surface of the spiral colon, with edematous and inflamed mesenteric lymph nodes. The presence of Gram-positive bacilli adhered to the surface of the necrotic mucosa in parts of the intestinal tract were found, which reinforces the diagnosis of the action of ITX (Redondo et al., 2017).

Although the diagnosis is based on the presence of toxins in the intestinal contents, it is important to develop new indicators of enterotoxemia, which may be combined with other methods, especially the animal's history, clinical signs, necropsy findings and histopathology of the organs with lesions to obtain faster and more accurate methods. In addition, a comparative study of the clinical picture and the histopathologic structure is important to reveal the pathogenesis and the diagnosis of the infections caused by $C$. perfringens toxins in different species and to elucidate the characteristics of the infection and the action of the toxins (Alves et al., 2014; Silva and Lobato, 2015; Santana et al., 2018). The interpretation of histological findings from bovine intestinal sections combined with studies in animal models in preclinical trials can contribute to the development of these methods.

Murine models have been used to elucidate several mechanisms of pathogen infection. These models do not develop signs of clinical disease as described in humans or other mammals; however, they are important, since they develop an acute infection and associated pathological changes (Simpson et al., 2018). Scientific studies have demonstrated the importance of murine models in elucidating mechanisms associated with disease pathogenesis, host response dynamics and the action of Clostridium $\mathrm{sp}$ toxins during infection (Ismail and Omoush, 2019). Recently, Batah et al., (2017) used C57BL/ 6 models to evaluate the action of $C$. 
difficile toxin in the inflammatory response of the epithelial tissue, causing signs of infection due to the appearance of ruffled hairs, reduced metabolic activity, high inflammation index, mucosal edema, epithelial lesions, and loss of goblet cells. It is important to advance in the elucidation of ITX participation in simulated studies with the main toxins of $C$. perfringens that are involved in the intestinal lesions of infected animals. In vivo tests using a murine model can contribute to advance the ITX specificity and other binary toxins from Clostridium sp in intestinal lesions. These models develop symptoms of the infection, contributing to explain the intestinal lesions caused by each species of $C$. perfringens. Murine model is a practical and rapid animal model that uses mice throughout the clinical evaluation phase, and can be used in the analysis of fluid in the small intestine from a dose of toxin (Assis-Rodrigues et al., 2019). Reports already described the action of ITX in the murine model that showed changes in intestinal permeability, induction of necrosis, degenerative changes in the mucosal epithelium, intestinal motility, highlighting the central role of ITX in hemorrhagic enteritis caused by $C$. perfringens type $\mathrm{E}$ (Redondo et al., 2017).

\section{CONCLUSION}

In hemorrhagic necrotic enteritis, there is the participation of ITX due to the detection of the toxin in intestinal fluids and by isolation of the pathogen in infected animals. However, there are still difficulties in a rapid differential diagnosis between infections caused by ITX and those caused by other binary toxins.

\section{FUTURE PERSPECTIVES}

A possible solution can be found in the advance of knowledge about the molecular interaction mechanisms of Ia and Ib of ITX and the interaction mechanism of the other binary toxins of Clostridium sp that act on the host cell's globular actin, depolymerizing and disorganizing the intercellular junctions. This will allow the development of new enterotoxemia indicators to establish quick and accurate differential diagnosis methods of ITX action in the infectious process.

\section{ACKNOWLEDGEMENTS}

We acknowledge Prof. Dr. Francisco Carlos F. Lobato (FCFL) - Veterinary School from the Federal University of Minas Gerais for his availability for technical review, the Biotechnology Graduate Program and the ViceRectory of Research from the Federal University of Tocantins. And also, HSB, FCA, MGS, ASRC performed scope and writing work. DSM, MKCF, EEO, LAMM revised English language. EMS, IVB, ASRC, MGS technical aspects of the work analysis.

\section{CONFLICT OF INTEREST}

The authors declare that there is no conflict of interest.

\section{BIBLIOGRAPHIC REFERENCES}

Alves, G. G.; R. A. M. de Ávila; Chávez-Olórtegui, C. D.; Lobato, F. C. F. (2014). Clostridium perfringens epsilon toxin: The third most potent bacterial toxin known. Anaerobe. 30: 102-107. doi: 10.1016/j.anaerobe.2014.08.016

Assis-Rodrigues, M.; Rodrigues-Sartori, S.; Santos-Totaro, P.; Pinto da Matta, S. (2019). 
Hystometric evaluation of nickel chronic exposure effects on large instestine of adult Wistar male rats. Revista de Ciencias Agrícolas. 36 (E): 21-30. doi: 10.22267/rcia.1936E.103

Awad, M. M.; Bryant, A. E.; Stevens, D. L.; Rood, J. I. (1995). Virulence studies on chromosomal $\alpha$-toxin and $\Theta$-toxin mutants constructed by allelic exchange provide genetic evidence for the essential role of $\alpha$-toxin in Clostridium perfringens-mediated gas gangrene. Molecular Microbiology. 15: 191-202. doi: 10.1111/ j.1365-2958.1995.tb02234.x

Batah, J.; Kobeissy, H.; Pham, P. T. B.; DenèveLarrazet, C.; Kuehne, S.; Collignon, A.; JanoirJouveshomme, C.; Marvaud, J. C.; Kansau, I. (2017). Clostridium difficile flagella induce a pro-inflammatory response in intestinal epithelium of mice in cooperation with toxins. Scientific Reports. 7: 1-10. doi: 10.1038/ s41598-017-03621-z

Borriello, S. P.; Carman, R. J. (1983). Association of iota-like toxin and Clostridium spiroforme with both spontaneous and antibioticassociated diarrhea and colitis in rabbits. Journal of Clinical Microbiology. 17 (3): 414 418. doi: 0095-1137/83/030414-05\$02.00/0

Brandi, I. V.; Mozzer, O. D.; Vander Jorge, E.; Passos, F. J. V.; Passos, F. M. L.; Cangussu, A. S. R.; Sobrinho, E. M. (2014). Growth conditions of clostridium perfringens type B for production of toxins used to obtain veterinary vaccines. Bioprocess and biosystems engineering. 37 (9): 1737-1742. doi: 10.1007/s00449-014-1146-0

Brandi, I. V.; Santos, E. M. S.; de Carvalho, B. M. A.; Durães, C. A. F.; Farias, P. K. S.; Sari, R. S.; Junior, A. P. (2016). Total combining power: Technique for the evaluation of the quality control process of clostridiosis vaccines. Journal of microbiological methods. 130: 164168. doi: 10.1016/j.mimet.2016.08.023

Carman, R. J.; Borriello, S. P. (1984). Infectious nature of Clostridium spiroforme-mediated rabbitenterotoxaemia.Veterinarymicrobiology. 9 (5): 497-502. doi: 10.1016/03781135(84)90070-1
Chakravorty, A.; Awad, M. M.; Hiscox, T. J.; Cheung, J. K.; Choo, J. M.; Lyras, D.; Rood, J. I. (2014). Opioid analgesics stop the development of clostridial gas gangrene. Journal of Infectious Diseases. 210: 483-492. doi: 10.1093/infdis/ jiu101

Diab, S. S.; Kinde, H.; Moore, J.; Shahriar, M. F.; Odani, J.; Anthenill, L.; Uzal, F. A. (2012). Pathology of Clostridium perfringens type $\mathrm{C}$ enterotoxemia in horses. Veterinary Pathology. 49 (2): 255263. doi: $10.1177 / 0300985811404710$

Domenighini, M.; Rappuoli, R. (1996). Three conserved consensus sequences identify the NAD-binding site of ADP-ribosylating enzymes, expressed by eukaryotes, bacteria and T-even bacteriophages. Molecular Microbiology. 21: 667-674 doi: 10.1046/j.13652958.1996.321396.x

Felix, M. K. C.; Deusdará, T. T.; Santos, L. S. S.; Aguiar, R. W. S.; Corrêa, R. F. T.; Brandi, I. V.; Cangussu, A. S. R. (2019). Inactivated alpha toxin from Clostridium novyi type B in nanoemulsion protect partially protects Swiss mice from lethal alpha toxin challenge. Scientific reports. 9 (1): 1-9. doi: 10.1038/s41598-01950683-2

Ferrarezi, M. C.; Cardoso, T. C.; Dutra, I. S. (2008). Genotyping of Clostridium perfringens isolated from calves with neonatal diarrhea. Anaerobe. 14: 328-331. doi: 10.1016/j. anaerobe.2008.12.001

Filho, E. J. F.; Carvalho, A. U.; Assis, R. A.; Lobato, F. F.; Rachid, M. A.; Carvalho, A. A.; Ferreira, P. M.; Nascimento, R. A.; Fernandes, A. A.; Vidal, J. E.; Uzal, F. A. (2009). Clinicopathologic features of experimental Clostridium perfringens type D enterotoxemia in cattle. Veterinary Pathology. 46: 1213-1220. doi: 10.1354/vp.08-VP-0304$\mathrm{U}-\mathrm{FL}$

Fleming, S. (1985). Enterotoxemia in neonatal calves. Veterinary Clinics of North America: Food Animal Practice. 1 (3): 509-514. doi: 10.1016/S0749-0720(15)31299-8 
Freedman, J. C.; Theoret, J. R.; Wisniewski, J. A.; Uzal, F. A.; Rood, J. I.; McClane, B.A. (2015). Clostridium perfringens type A-E toxin plasmids. Research in Microbiology. 166: 264279. doi: 10.1016/j.resmic.2014.09.004

Fuentes, L.; Lebenkoff, S.; White, K.; Gerdts, C.; Hopkins, K.; Potter, J. E.; Grossman, D.; Project, P. E.; Sciences, R. (2016). Animal models to study the pathogenesis of human Clostridium perfringens infections. Veterinary Microbiology. 93: 292-297. doi: 10.1016/j. vetmic.2015.02.013.Animal

Gibert, M.; Marvaud, J. C.; Pereira, Y.; Hale, M. L.; Stiles, B. G.; Boquet, P.; Lamaze, C.; Popoff, M. R. (2007). Differential requirement for the translocation of clostridial binary toxins: Iota toxin requires a membrane potential gradient. FEBS Letters. 581: 1287-1296. doi: 10.1016/j. febslet.2007.02.041

Gibert, M.; Monier, M. N.; Ruez, R.; Hale, M. L.; Stiles, B. G.; Benmerah, A.; Johannes, L.; Lamaze, C.; Popoff, M. R. (2011). Endocytosis and toxicity of clostridial binary toxins depend on a clathrin-independent pathway regulated by Rho-GDI. Cellular Microbiology. 13: 154170. doi: 10.1111/j.1462-5822.2010.01527.x

Gibert, M.; Petit, L.; Raffestin, S.; Okabe, A.; Popoff, M. R. (2000). Clostridium perfringens iotatoxin requires activation of both binding and enzymatic components for cytopathic activity. Infection and Immunity. 68: 3848-3853. doi: 10.1128/IAI.68.7.3848-3853.2000

Ghoneim, N. H.; Hamza, D. A. (2017). Epidemiological studies on Clostridium perfringens food poisoning in retail foods. Rev. Sci. Tech. 36 (3): 1025-1032. doi: 10.20506/ rst.36.3.2734

Harada, M.; Kondoh, M.; Ebihara, C.; Takahashi, A.; Komiya, E.; Fujii, M.; Mizuguchi, H.; Tsunoda, S. I.; Horiguchi, Y.; Yagi, K.; Watanabe, Y. (2007). Role of tyrosine residues in modulation of claudin-4 by the C-terminal fragment of Clostridium perfringens enterotoxin. Biochemical Pharmacology. 73: 206-214. doi: 10.1016/j.bcp.2006.10.002
Harkness, J. M.; Li, J.; McClane, B. A. (2012). Identification of a lambda toxin-negative Clostridium perfringens strain that processes and activates epsilon prototoxin intracellularly. Anaerobe. 18: 546-552. doi: 10.1016/j. anaerobe.2012.09.001

Ismail, Z. B; Omoush, F. (2019). Abomasal displacement in neonatal dairy calves: Review of recent literature with special emphasis on abomasal torsion. Veterinary World. 12: 1121-1125. doi: 10.14202/ vetworld.2019.1121-1125

Jewell, S. A.; Titball, R. W.; Huyet, J.; Naylor, C. E.; Basak, A. K.; Gologan, P.; Winlove, C. P.; Petrov, P. G. (2015). Clostridium perfringens $\alpha$-toxin interaction with red cells and model membranes. Soft Matter. 11: 7748-7761. doi: 10.1039/c5sm00876j

Keyburn, A. L.; Yan, X. X.; Bannam, T. L.; Van Immerseel, F.; Rood, J. I.; Moore, R. J. (2010). Association between avian necrotic enteritis and Clostridium perfringens strains expressing NetB toxin. Veterinary Research. 41. doi: $10.1051 /$ vetres/2009069

Kim, H.; Byun, J.; Roh, I.; Bae, Y.; Lee, M.; Kim, B.; Songer, J. G.; Jung, B. Y. (2013). First isolation of Clostridium perfringens type E from a goat with diarrhea. Anaerobe. 22: 141-143. doi: 10.1016/j.anaerobe.2013.06.009

Knapp, 0.; Benz, M.; Popoff, R. (2016). Pore-forming activity of clostridial binary toxins. Biochimica et Biophysica Acta - Biomembranes. 1858: 512525. doi: 10.1016/j.bbamem.2015.08.006

Knapp, O.; Maier, E.; Benz, R.; Geny, B.; Popoff, M. R. (2009). Identification of the channelforming domain of Clostridium perfringens Epsilon-toxin (ETX). Biochimica et Biophysica Acta - Biomembranes. 1788: 2584-2593. doi: 10.1016/j.bbamem.2009.09.020

Li, J.; Adams, V.; Bannam, T. L.; Miyamoto, K.; Garcia, J. P.; Uzal, F. A.; Rood, J. I.; McClane, B. A. (2013). Toxin Plasmids of Clostridium perfringens. Microbiology and Molecular Biology Reviews. 77: 208-233. doi: 10.1128/mmbr.00062-12 
Lobato, F. C. F.; Moro, E.; Umehara, O.; Assis, R. A.; Martins, N. E.; Gonçalves, L. C. B. (2000). Avaliação da resposta de antitoxinas beta e épsilon de Clostridium perfringens induzidas embovinos ecoelhosporseisvacinascomerciais no Brasil. Arquivo Brasileiro de Medicina Veterinária e Zootecnia. 52 (4): 313-318. doi: 10.1590/S0102-09352000000400004

Lobato, F. C. F.; Salvarani, F. M.; Gonçalves, L. A.; Pires, P. S.; Silva, R. O. S.; Alves, G. G.; Pereira, P. L. L. (2013). Clostridioses dos animais de produção. Veterinaria e zootecnia. 20: 29-48.

Manteca, C.; Daube, G.; Jauniaux, T.; Linden, A.; Pirson, V.; Detilleux, J.; Ginter, A.; Coppe, P.; Kaeckenbeeck, A.; Mainil, J. G. (2002). A role for the Clostridium perfringens beta2 toxin in bovine enterotoxaemia? Veterinary microbiology. 86: 191-202. doi: 10.1016/ s0378-1135(02)00008-1

Mehdizadeh-Gohari, I.; Navarro, M. A.; Li, J.; Shrestha, A.; Uzal, F.; McClane, B. A. (2021). Pathogenicity and virulence of Clostridium perfringens. Virulence. 12: 723-753. doi: $10.1080 / 21505594.2021 .1886777$

Miclard, J.; Jäggi, M.; Sutter, E.; Wyder, M.; Grabscheid, B.; Posthaus, H. (2009a). Clostridium perfringens beta-toxin targets endothelial cells in necrotizing enteritis in piglets. Veterinary Microbiology. 137: 320-325. doi: 10.1016/j.vetmic.2009.01.025

Miclard, J.; Van-Baarlen, J.; Wyder, M.; Grabscheid, B.; Posthaus, H. (2009b). Clostridium perfringens $\beta$-toxin binding to vascular endothelial cells in a human case of enteritis necroticans. Journal of Medical Microbiology. 58: 826-828. doi: 10.1099/jmm.0.008060-0

Minami, J.; Katayama, S.; Matsushita, O.; Matsushita, C.; Okabe, A. (1997). Lambdatoxin of Clostridium perfringens activates the precursor of epsilon-toxin by releasing its $\mathrm{N}$ - and C-terminal peptides. Microbiology and Immunology. 41: 527-535. doi: 10.1111/ j.1348-0421.1997.tb01888.x
Miyashiro, S.; Baldassi, L.; Nassar, A. (2009). Genotyping of Clostridium perfringens associated with sudden death in cattle. Journal of Venomous Animals and Toxins including Tropical Diseases. 15: 12-14. doi: 10.1590/ S1678-91992009000300010

Moreira, G. M. S. G.; Salvarani, F. M.; Da-Cunha, C. E. P.; Mendonça, M.; Moreira, Â. N.; Gonçalves, L. A.; Conceição, F. R. (2016). Immunogenicity of a trivalent recombinant vaccine against Clostridium perfringens alpha, beta, and epsilon toxins in farm ruminants. Scientific reports. 6 (1): 1-9. doi: 10.1038/srep22816

Nagahama, M.; Nagayasu, K.; Kobayashi, K.; Sakurai, J. (2002). Binding component of Clostridium perfringens iota-toxin induces endocytosis in vero cells. Infection and Immunity. 70: 1909-1914. doi: 10.1128/ IAI.70.4.1909-1914.2002

Nagahama, M.; Sakaguchi, Y.; Kobayashi, K.; Ochi, S.; Sakurai, J. (2000). Characterization of the enzymatic component of Clostridium perfringens iota-toxin. Journal of Bacteriology. 182: 2096-2103. doi: 10.1128/JB.182.8.20962103.2000

Nagahama, M.; Umezaki, M.; Tashiro, R.; Oda, M.; Kobayashi, K.; Shibutani, M.; Takagishi, T.; Ishidoh, K.; Fukuda, M.; Sakurai, J. (2012). Intracellular trafficking of Clostridium perfringens iota-toxin b. Infection and Immunity. 80: 3410-3416. doi: 10.1128/ IAI.00483-12

Navarro, M. A.; McClane, B. A.; Uzal, F. A. (2018). Mechanisms of action and cell death associated with Clostridium perfringens toxins. Toxins. 10: 1-21. doi: 10.3390/toxins10050212

Navarro, M. A.; Shrestha, A.; Freedman, J. C.; Beingesser, J.; McClane, B. A.; Uzal, F. A. (2019). Potential therapeutic effects of mepacrine against clostridium perfringens enterotoxin in a mouse model of enterotoxemia. Infection and Immunity. 87: 1-10. doi: 10.1128/ IAI.00670-18 
Park, M.; Deck, J.; Foley, S. L.; Nayak, R.; Songer, J. G.; Seibel, J. R.; Rafii, F. (2016). Diversity of Clostridium perfringens isolates from various sources and prevalence of conjugative plasmids. Anaerobe. 38: 25-35. doi: 10.1016/j. anaerobe.2015.11.003

Perelle, S.; Domenighini, M.; Popoff, M. R. (1996). Evidence that Arg-295, Glu-378, and Glu380 are active-site residues of the ADPribosyltransferase activity of iota toxin. FEBS Letters. 395: 191-194. doi: 10.1016/00145793(96)01035-6

Prescott, J. F.; Parreira, V. R.; MehdizadehGohari, I.; Lepp, D.; Gong, J. (2016). The pathogenesis of necrotic enteritis in chickens: what we know and what we need to know: a review. Avian Pathology. 45: 288-294. doi: 10.1080/03079457.2016.1139688

Redondo, L. M.; Carrasco, J. M. D.; Redondo, E. A.; Delgado, F.; Fernández-Miyakawa, M. E. (2015). Clostridium perfringens type E virulence traits involved in gut colonization. PLOS ONE. 10: 1-18. doi: 10.1371/journal.pone.0121305

Redondo, L. M.; Farber, M.; Venzano, A.; Jost, B. H.; Parma, Y. R.; Fernandez-Miyakawa, M. E. (2013). Sudden death syndrome in adult cows associated with Clostridium perfringens type E. Anaerobe. 20: 1-4. doi: 10.1016/j. anaerobe.2013.01.001

Redondo, L. M.; Redondo, E. A.; Dailoff, G. C.; Leiva, C. L.; Diaz-Carrasco, J. M.; Bruzzone, 0. A.; Cangelosi, A.; Geoghegan, P.; FernandezMiyakawa, M. E. (2017). Effects of Clostridium perfringens iota toxin in the small intestine of mice. Anaerobe. 48: 83-88. doi: 10.1016/j. anaerobe.2017.07.007

Richard, J. F.; Mainguy, G.; Gibert, M.; Marvaud, J. C.; Stiles, B. G.; Popoff, M. R. (2002). Transcytosis of iota-toxin across polarized CaCo-2 cells. Molecular Microbiology. 43: 907-917. doi: 10.1046/j.1365-2958.2002.02806.x

Rood, J. I.; Adams, V.; Lacey, J.; Lyras, D.; McClane, B. A.; Melville, S. B.; Moore, R. J.; Popoff, M. R.; Sarker, M. R.; Songer, J. G.; Uzal, F. A.;
Van-Immerseel, F. (2018). Expansion of the Clostridium perfringens toxin-based typing scheme. Anaerobe. 53: 5-10. doi: 10.1016/j. anaerobe.2018.04.011

Rood, J. I.; Keyburn, A. L.; Moore, R. J. (2016). NetB and necrotic enteritis: the hole movable story. Avian Pathology. 45: 295-301. doi: 10.1080/03079457.2016.1158781

Sakurai, J.; Nagahama, M.; Oda, M.; Tsuge, H.; Kobayashi, K. (2009). Clostridium perfringens iota-toxin: structure and function. Toxins. 1: 208-228. doi: 10.3390/toxins 1020208

Santana, J. A.; Ferreira, A. C. D. A.; Souza, M. D. C. C. D.; Moreira, M. A. S.; Lima, M. C.; Cruz, D. S. G.; Lobato, F. C. F.; Silva, R. O. S. (2018). Isolation and genotyping of clostridium perfringens from goats in Minas Gerais, Brazil. Ciencia Rural. 48: 5-8. doi: 10.1590/0103-8478cr20180101

Sari, R. S.; Almeida, A. C.; Cangussu, A. S. R.; Jorge, E. V.; Mozzer, D. O.; Santos, H. O.; Quintilio, W.; Brandi, I. V.; Andrade, V. A.; Miguel, A. S. M.; Santos, E. M. S. (2016). Anti-botulism single-shot vaccine using chitosan for protein encapsulation by simple coacervation. Anaerobe. 42: 182-187.

Sayeed, S.; Uzal, F. A.; Fisher, D. J.; Saputo, J.; Vidal, J. E.; Chen, Y., Gupta, P.; Rood, J. I.; McClane, B. A. (2008). Beta toxin is essential for the intestinal virulence of Clostridium perfringens type $\mathrm{C}$ disease isolate CN3685 in a rabbit ileal loop model. Molecular Microbiology. 67: 15-30. doi: 10.1111/j.1365-2958.2007.06007.x

Schmidt, G.; Papatheodorou, P.; Aktories, K. (2015). Novel receptors for bacterial protein toxins. Current Opinion in Microbiology. 23: 5561. doi: 10.1016/j.mib.2014.11.003

Schumacher, V. L.; Martel, A.; Pasmans, F.; van-Immerseel, F.; Posthaus, H. (2013). Endothelial binding of beta toxin to small intestinal mucosal endothelial cells in early stages of experimentally induced Clostridium perfringens type $\mathrm{C}$ enteritis in pigs. Veterinary Pathology. 50: 626-629. doi: 10.1177/0300985812461362 
Shrestha, A.; Uzal, F. A.; McClane, B. A. (2019). Enterotoxic Clostridia: Clostridium perfringens Enteric Diseases. Gram-Positive Pathogens. 6: 977-990. doi: 10.1128/9781683670131.ch60

Silva, R. O. S.; Lobato, F. C. F. (2015). Clostridium perfringens: A review of enteric diseases in dogs, cats and wild animals. Anaerobe. 33: 1417. doi: 10.1016/j.anaerobe.2015.01.006

Silva, R. O. S.; Oliveira-Junior, C. A.; Guedes, R. M. C.; Lobato, F. C. F. (2015). Clostridium perfringens: a review of the disease in pigs, horses and broiler chickens. Ciência Rural. 45: 1027-1034. doi: 10.1590/0103-8478cr20140927

Simpson, K. M.; Callan, R. J.; Van-Metre, D. C. (2018). Clostridial Abomasitis and Enteritis in Ruminants. Veterinary Clinics of North America: Food Animal Practice. 34: 155-184. doi: 10.1016/j.cvfa.2017.10.010

Smedley, J. G.; McClane, B. A. (2004). Fine mapping of the $\mathrm{N}$-terminal cytotoxicity region of Clostridium perfringens enterotoxin by sitedirected mutagenesis. Infection and Immunity. 72: 6914-6923. doi: 10.1128/IAI.72.12.69146923.2004

Sobrinho, E. M.; Almeida, A. C.; Brandi, I. V.; Colen, F.; Lobato, F. C. F.; Cangussu, A. S. R.; Quintilio, W.; Santos, H. O.; Sari, R. S. (2014). ELISA and modified toxin-binding inhibition test for quality control of the clostridial vaccine processes. Arquivo Brasileiro de Medicina Veterinaria e Zootecnia. 66: 713-720. doi: 10.1590/1678-41625407

Sobrinho, E. M.; Cangussu, A. S. R.; Brandi, I. V.; Sari, R. S.; Almeida, A. C.; Colen,F.; Quintilio, W.; Santos, H. O. (2010). Modified toxin-binding inhibition (ToBI) test for epsilon antitoxin determination in serum of immunized rabbits. Veterinary Immunology and Immunopathology. 138: 129-133. doi: 10.1016/j.vetimm.2010.07.007

Songer, J. G. (1996). Clostridial enteric diseases of domestic animals. Clinical Microbiology Reviews. 9: 216-234. doi: 10.1128/cmr.9.2.216
Songer, J. G.; Miskimmins, D. W. (2004). Clostridium perfringens type $\mathrm{E}$ enteritis in calves: Two cases and a brief review of the literature. Anaerobe. 10: 239-242. doi: 10.1016/j.anaerobe.2004.05.001

Stiles, B. G.; Wilkins, T. D. (1986). Purification and characterization of Clostridium perfringens iota toxin: Dependence on two nonlinked proteins for biological activity. Infection and Immunity. 54: 683-688. doi: 10.1128/ iai.54.3.683-688.1986

Szklarczyk D, Gable A.L.; Nastou, K.C.; Lyon, D.; Kirsch, R.; Pyysalo, S.; Doncheva, N.T.; Legeay, M.; Fang, T.; Bork, P.; Jensen, L.J.; von Mering, C. (2021). The STRING database in 2021: customizable protein-protein networks, and functional characterization of user-uploaded gene/measurement sets. Nucleic Acids Res. 2021 Jan 8;49(D1):D605-12

Takahashi, A.; Komiya, E.; Kakutani, H.; Yoshida, T.; Fujii, M.; Horiguchi, Y.; Mizuguchi, H.; Tsutsumi, Y.; ichi-Tsunoda, S.; Koizumi, N.; Isoda, K.; Yagi, K.; Watanabe, Y.; Kondoh, M. (2008). Domain mapping of a claudin-4 modulator, the $\mathrm{C}$-terminal region of $\mathrm{C}$-terminal fragment of Clostridium perfringens enterotoxin, by site-directed mutagenesis. Biochemical Pharmacology. 75: 1639-1648. doi: 10.1016/j. bcp.2007.12.016

Takehara, M.; Takagishi, T.; Seike, S.; Oda, M.; Sakaguchi, Y.; Hisatsune, J.; Ochi, S.; Kobayashi, K.; Nagahama, M. (2017). Cellular entry of Clostridium perfringens iota-toxin and Clostridium botulinum C2 toxin. Toxins. 9: 8-11. doi: 10.3390/toxins9080247

Tsuge, H.; Nagahama, M.; Nishimura, H.; Hisatsune, J.; Sakaguchi, Y.; Itogawa, Y.; Katunuma, N.; Sakurai, J. (2003). Crystal structure and site-directed mutagenesis of enzymatic components from Clostridium perfringens Iota-toxin. Journal of Molecular Biology. 325: 471-483. doi: 10.1016/S00222836(02)01247-0 
Tsuge, H.; Nagahama, M.; Oda, M.; Iwamoto, S.; Utsunomiya, H.; Marquez, V. E.; Katunuma, N.; Nishizawa, M.; Sakurai, J. (2008). Structural basis of actin recognition and arginine ADPribosylation by Clostridium perfringens t-toxin. Proceedings of the National Academy of Sciences of the United States of America. 105: 7399-7404. doi: 10.1073/pnas.0801215105

Uzal, F. A. (2004). Diagnosis of Clostridium perfringens intestinal infections in sheep and goats. Anaerobe. 10: 135-143. doi: 10.1016/j. anaerobe.2003.08.005

Uzal, F. A.; Kelly, W. R. (1997). Effects of the intravenous administration of Clostridium perfringens type D epsilon toxin on young goats and lambs. Journal of Comparative Pathology. 116: 63-71. doi: 10.1016/S00219975(97)80044-8

Uzal, F. A.; Navarro, M. A.; Li, J.; Freedman, J. C.; Shrestha,A.; McClane, B.A. (2018). Comparative pathogenesis of enteric clostridial infections in humans and animals. Anaerobe. 53: 11-20. doi: 10.1016/j.anaerobe.2018.06.002

Uzal, F. A.; Sentíes-Cué, C. G.; Rimoldi, G.; Shivaprasad, H. L. (2016). Non- Clostridium perfringens infectious agents producing necrotic enteritis-like lesions in poultry. Avian Pathology. 45: 326-333. doi: 10.1080/03079457.2016.1159282

Uzal, F. A.; Vidal, J. E.; McClane, B. A.; Gurjar, A. A. (2010). Clostridium Perfringens Toxins Involved in Mammalian Veterinary Diseases. The open toxinology journal. 2: 24-42. doi: $10.2174 / 1875414701003010024$

Van Itallie, C. M.; Betts, L.; Smedley, J. G.; McClane, B. A.; Anderson, J. M. (2008). Structure of the Claudin-binding domain of Clostridium perfringens enterotoxin. Journal of Biological Chemistry. 283: 268-274. doi: 10.1074/jbc. M708066200

Vidal, J. E.; Ohtani, K.; Shimizu, T.; McClane, B. A. (2009). Contact with enterocyte-like Caco2 cells induces rapid upregulation of toxin production by Clostridium perfringens type $\mathrm{C}$ isolates. Cellular Microbiology. 11: 1306-1328. doi: 10.1111/j.1462-5822.2009.01332.x

Waters, M.; Raju, D.; Garmory, H. S.; Popoff, M. R.; Sarker, M. R. (2005). Regulated expression of the beta2-toxin gene (cpb2) in Clostridium perfringens type A isolates from horses with gastrointestinal diseases. Journal of Clinical Microbiology. 43: 4002-4009. doi: 10.1128/ JCM.43.8.4002-4009.2005

Wigelsworth, D. J.; Ruthel, G.; Schnell, L.; Herrlich, P.; Blonder, J.; Veenstra, T. D.; Carman, R. J.; Wilkins, T. D.; Van-Nhieu, G. T.; Pauillac, S.; Gibert, M.; Sauvonnet, N.; Stiles, B. G.; Popoff, M. R.; Barth, H. (2012). CD44 Promotes Intoxication by the Clostridial Iota-Family Toxins. PLoS ONE. 7: e51356. doi: 10.1371/ journal.pone.0051356

Yamada, T.; Yoshida, T.; Kawamoto, A.; Mitsuoka, K.; Iwasaki, K.; Tsuge, H. (2020). Cryo-EM structures reveal translocational unfolding in the clostridial binary iota toxin complex. Nature Structural \& Molecular Biology. 27: 288-296. doi: 10.1038/s41594-020-0388-6 